\title{
Utilization of Antenatal Care Services Among Pregnant Mothers in Wadajir District, Banadir Region-Mogadishu Somalia
}

\author{
Hussein Shire Jimale ${ }^{1, *}$, Ali Sheikh Mohamed Omer², Adan Yusuf Mahdi ${ }^{3}$, \\ Ahmed Mohamed Ahmed ${ }^{4}$ \\ ${ }^{1}$ Planning, Monitoring, Evaluation and Reporting Director, Somali Red Crescent Society, Mogadishu, Somalia \\ ${ }^{2}$ Postgraduate Center, Benadir University, Mogadishu, Somalia \& National Research Manager - Child Poverty, Save the Children, \\ Mogadishu, Somalia \\ ${ }^{3}$ Nutrition Technical Specialist, Save the Children, Mogadishu, Somalia \\ ${ }^{4}$ Deputy Executive Director of integrated Health Care, Somali Red Crescent Society, Mogadishu, Somalia \\ Email address: \\ pmerdirector@gmail.com (H. S. Jimale), alibotany2@gmail.com (A. S. M. Omer), adan.mahdi@savethechildren.org (A. Y. Mahdi), \\ ahmed.srcs@gmail.com (A. M. Ahmed) \\ ${ }^{*}$ Corresponding author
}

\section{To cite this article:}

Hussein Shire Jimale, Ali Sheikh Mohamed Omer, Adan Yusuf Mahdi, Ahmed Mohamed Ahmed. Utilization of Antenatal Care Services Among Pregnant Mothers in Wadajir District, Banadir Region-Mogadishu Somalia. Central African Journal of Public Health. Vol. 6, No. 6, 2020, pp. 320-325. doi: 10.11648/j.cajph.20200606.11

Received: August 25, 2020; Accepted: September 25, 2020; Published: October 30, 2020

\begin{abstract}
Antenatal care contributes to good pregnancy outcomes and often times benefits of antenatal care are dependent on the timing and quality of the care provided. Antenatal care is necessary to establish confidence between the woman and her health care provider, to individualize health promotion messages, and to identify and manage any maternal complications or risk factors. In low and middle income countries, complications of pregnancy and childbirth are the leading cause of death in women aged 1449 years. This study aimed at determining the level of utilization of antenatal care services among pregnant mothers in Wadajir district, Banadir region, Somalia. Ethical clearance was sought from Benadir University Ethics committee, consent was sought from respondents and confidentiality was maintained by not using any form of identification. Methodology: The study adopted a community based cross-sectional study design. The target population consisted of all pregnant mothers aged 14 years to 49 years within Wadajir district. Data collection instruments was researcher administered questionnaires. The questionnaire was administered to the pregnant mothers who met the inclusion criteria. Data collected was coded and entered into the computer for analysis using STATA version 12.0. Results of the study were summarized using percentages, tables and charts. Chi-square statistics were used to test for strength of association between the research variables and the relationship between the dependent and independent variables under study. Results: The study established that source of income (OR 4.312500, P value 0.0181), person living with the pregnant mothers (OR 4.312500, P value 0.0181) and marital status (OR 1.8, P.value 0.0478) were significantly associated with ANC utilization. About $29.0 \%$ of the respondents had visited ANC at least once and above for checkup while $29.7 \%$ had never visited ANC clinics. Only $18.9 \%$ of the pregnant mothers managed the recommended 4 and above ANC visits. Number of Pregnancies (Gravida), (OR 2.2, P-value 0.0029), pregnant mother complications during pregnancy (OR 4.312500, P value 1.8), influenced utilization of ANC services by pregnant mothers. Conclusion: There is law percentage of pregnant mothers having at least four ANC and above visits (18.9\%) as recommended by WHO, this indicates low utilization of antenatal care services. This study recommends customized ANC services targeting pregnant mothers to be established to increase utilization of ANC by pregnant mothers in Wadajir district. Stakeholders should come up with specific efforts towards enhancing staff motivation through introduction of incentives and better working environment.
\end{abstract}

Keywords: Utilization, Antenatal Care, Wadajir District 


\section{Introduction}

Antenatal care contributes to good pregnancy outcomes and often times benefits of antenatal care are dependent on the timing and quality of the care provided. Antenatal care is necessary to establish confidence between the woman and her health care provider, to individualize health promotion messages, and to identify and manage any maternal complications or risk factors. Globally, an estimated 287,000 maternal deaths occurred in 2010, of which $99 \%(284,000)$ occurred in developing countries $[1,2,4]$.

In regions with the highest rates of maternal mortality, such as sub-Saharan Africa and South Asia, even fewer women received at least four antenatal visits ( 49 per cent and 42 per cent, respectively). [3, 10]. In Somalia, Antenatal care services utilization is very low; countrywide an average of $26 \%$ of pregnant women receives at least one antenatal visit during their last pregnancy. Of these, the median number of visits is two and $9 \%$ of deliveries are assisted by skilled birth attendance $[5,6,8]$.

According to the latest estimates of the UN interagency group, 69,000 Somali children and 4,800 mothers are dying every year because of the poor health status and weak health system. One in four pregnant women attends antenatal care at least once. About $90 \%$ of women deliver at home, receive no postnatal care after delivery and newborn care is neglected. $[7,9,11]$

\section{Materials and Methods}

\subsection{Study Design, Site and Population}

The study was community-based cross sectional study design to investigate on level of utilization of antenatal care services among pregnant mothers. Semi-structured questionnaires were administered to all pregnant mothers. The inclusion criteria included all pregnant women who were residents of Wadajir district and were willing to participate in the study.

\subsection{Sample Size Calculation and Sampling Technique}

The formula below was used to determine the sample size. Fischer et al., 1998 cited in Kothari, $2004 \mathrm{n}=\mathrm{Z2} 2 \mathrm{p} * \mathrm{q} / \mathrm{d} 2$ considering the following assumptions: $95 \%$ confidence level, Proportion of pregnant mothers are $50 \%$. The sampling procedure was multi-stage cluster technique. A systematic sampling will be used to select a house hold jumping two houses. At household one pregnant mother was used. In case if the house has many pregnant mothers, one was randomly selected. A systematic sampling was used to select a house hold jumping two houses. At household one pregnant mother was used. In case if the house has many pregnant mothers, one was randomly selected. Using this technique, a total of 407 pregnant mothers for the study was obtained from the households include in the study. This continued until the desired sample size is achieved.

\subsection{Data Collection Tools}

Quantitative method of data collection was employed to investigate the utilization of antenatal care among pregnant women in Wadajir district. Quantitative data was obtained using semi-structured questionnaire to obtain information on level of antenatal care practices of the pregnant women, health factors and socio-demographics characteristics of the pregnant mothers in wadajir district.

\subsection{Data Quality Control}

In this study, pretesting of the instruments was done in Dharkenley district, Benadir region Somalia. Dharkenley district was chosen by the researcher because it reflects the same characteristics as those of Wadajir district.

\subsection{Data Processing and Analyzing}

After all data is collected, it was cleaned and coded for analysis. After data cleaning, the data was coded and entered in the computer for analysis using the Statistical Package for Social Sciences (SPSS) 20.0. This study yielded quantitative data. The results of data analysis were presented using frequency distribution tables and bar graphs. The information presented using proportions and percentages in tables, figures. The chisquare $(\chi 2)$ test was then used to assess differentials existing between various characteristics of pregnant women on utilization of antenatal care services. Cross tabulation was used to display the nature of association between the study variables. P- Value of less than 0.05 was considered statistically significant.

\subsection{Ethical Considerations}

Approval to conduct the study was sought from Graduate school and clearance was sought from Benadir University Ethics and Review Committee. Permit was obtained from by the Ministry of Health Somalia, Federal Government of Somalia.

\section{Results}

\subsection{Socio-demographic Characteristics of Caretakers}

A total of 407 pregnant mothers between the age of 14 and 49 years and were residents of Wadajir district were interviewed for the study, with a response rate of $100 \%$. Socio-demographic information sought from them included age, marital status, level of education, main source of income, person living with them, reason (s) for leaving school, employment status, access to TV and ownership or access to mobile phone. The results were as follows.

Table 1. Socio-demographic characteristics of the pregnant women.

\begin{tabular}{lll}
\hline Variable & Frequency & Percentage (\%) \\
\hline Age group & & \\
$14-20$ & 67 & 16.5 \\
$21-25$ & 111 & 27.3 \\
$26-30$ & 130 & 31.9 \\
$31-35$ & 42 & 10.3 \\
\hline
\end{tabular}




\begin{tabular}{lll}
\hline Variable & Frequency & Percentage (\%) \\
\hline $36-40$ & 30 & 7.4 \\
41 above & 27 & 6.6 \\
Total & 407 & 100 \\
Level of Education & & \\
College/university & 114 & 28 \\
Secondary & 125 & 30.7 \\
Primary level & 77 & 18.9 \\
None & 91 & 22.4 \\
Total & 407 & 100 \\
Persons Living With & & \\
Spouse & 170 & 41.8 \\
Parents & 159 & 39.1 \\
Relatives & 68 & 16.7 \\
Other & 10 & 2.5 \\
Total & 407 & 100 \\
Source of income & & \\
Self & 164 & 40.3 \\
Spouse & 130 & 31.9 \\
Parents & 58 & 14.3 \\
Other & 55 & 13.5 \\
Total & 407 & 100 \\
Employment & & \\
Employed & 201 & 49.4 \\
Not Employed & 206 & 50.6 \\
Total & 407 & 100 \\
\hline & &
\end{tabular}

\subsection{Utilization of ANC Services Among Pregnant Mothers}

The study established that nearly a twenty percent of the pregnant mothers (18.9\%) had attended four or more antenatal visits during their current pregnancy. Nearly half of the respondents $(51.4 \%)$ managed less than four visits while $(29.7 \%)$ had not made any visit to Antenatal care services. (Figure 1)

\subsection{Association Between Socio-Demographic Factors With ANC Service Utilization Service Utilization}

The results in Table 2 show that marital status, person living with, and source of income were found to be significant.

Marital status was found to be associated with utilization of ANC service. Divorced mothers were 2 times more likely to utilize ANC service compared to mothers who were married (OR 1.8, P-value 0.0478).

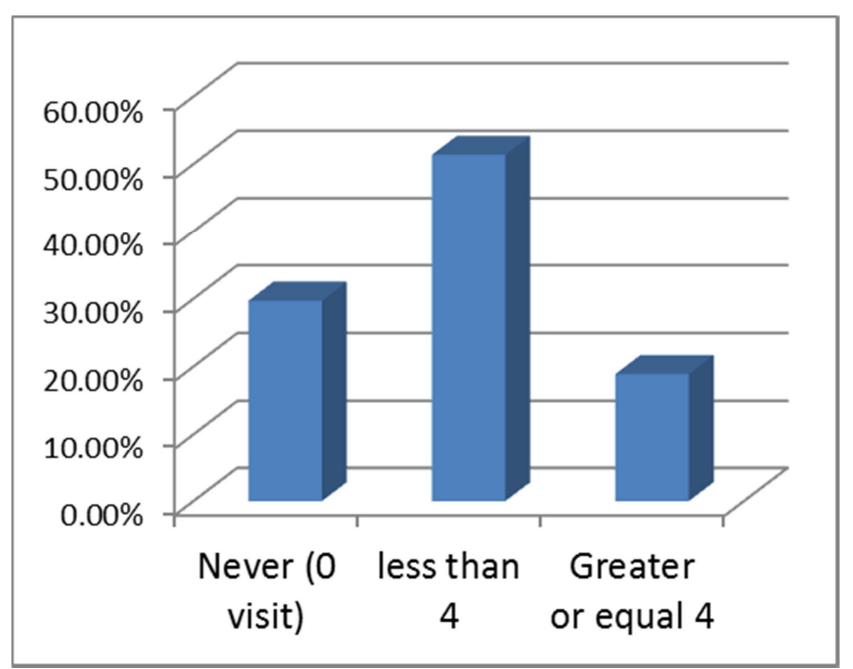

Figure 1. Number of times pregnant mothers visited ANC Clinics for checkups.

Person living with pregnant mother was found to be associated with level of utilization of ANC service. Pregnant mothers living with others were 4 times more likely to utilize ANC service compared to mothers whose parents, spouse and self living with (OR 4.312500, $\mathrm{P}$ value 0.0181) respectively.

Source of income was found to be associated with level of utilization of ANC service. Source of income from others was 4 times more likely to utilize ANC service compared to source of income from parents and spouse (OR 4.312500, $\mathrm{P}$ value 0.0181 ) respectively.

Other demographic factors such as: employment status and educational level were not significantly associated with level of utilization of ANC service.

Table 2. Association between Socio-Demographic Factors with ANC Service Utilization service utilization.

\begin{tabular}{|c|c|c|c|c|}
\hline Variable & $\mathbf{N}$ & ANC utilization N (\%) & Odd Ratio & p-value \\
\hline \multicolumn{5}{|l|}{ Marital status } \\
\hline Married & 332 & 81.57 & 1.000000 & \\
\hline Divorced & 64 & 15.72 & 1.848576 & 0.0478 \\
\hline Other & 11 & 2.7 & 0.472414 & 0.4694 \\
\hline \multicolumn{5}{|l|}{ Employment status } \\
\hline Employed & 201 & 49.39 & 1.000000 & . \\
\hline Not employed & 206 & 50.61 & 1.068056 & 0.7951 \\
\hline \multicolumn{5}{|l|}{ Person living with } \\
\hline Self & 170 & 41.77 & 1.000000 & \\
\hline Spouse & 159 & 39.07 & 0.921756 & 0.7761 \\
\hline Parents & 68 & 16.71 & 0.924107 & 0.8331 \\
\hline Other & 10 & 2.46 & 4.312500 & 0.0181 \\
\hline \multicolumn{5}{|l|}{ Source of income } \\
\hline Self & 164 & 40.29 & 1.000000 & . \\
\hline Spouse & 130 & 31.94 & 0.921756 & 0.7761 \\
\hline Parents & 58 & 14.25 & 0.924107 & 0.8331 \\
\hline Other & 55 & 13.51 & 4.312500 & 0.0181 \\
\hline \multicolumn{5}{|l|}{ Educational level } \\
\hline College/University & 114 & 28.01 & 1.000000 & \\
\hline Secondary level & 125 & 30.71 & 0.630631 & 0.2221 \\
\hline
\end{tabular}




\begin{tabular}{lllll}
\hline Variable & N & ANC utilization N (\%) & Odd Ratio & p-value \\
\hline Primary level & 77 & 18.92 & 1.875000 & 0.0780 \\
None & 91 & 22.36 & 1.691176 & 0.1302 \\
\hline
\end{tabular}

*= significant where $\mathrm{P}$-value $<0.05, \mathrm{OR}=$ Odds ratio.

\subsection{Association Between Obstetric Factors With ANC Service Utilization}

The results in Table 3 show that Number of Pregnancies (Gravida), and Complications during pregnancy were found to be significant.

Number of Pregnancies (Gravida) was found to be associated with level of utilization of ANC service. Mothers who had 6-11 Gravida were 2 times more likely to utilize of ANC service compared to 1-5 and 12-above Gravida (OR
2.2, P-value 0.0029). Mothers who had complications during pregnancy were found to be associated with level of utilization of ANC service. Pregnant mothers who had no complications during pregnancy were 2 times more likely to utilize of ANC service compared to mothers who had complications during pregnancy (OR 4.312500, $\mathrm{P}$ value 1.8).

Other obstetric factors such as: Number of children mothers have given birth (Parity) was not significantly associated with level of utilization of ANC service.

Table 3. Association between Obstetric Factors and Utilization Of ANC Services.

\begin{tabular}{|c|c|c|c|c|c|}
\hline \multirow{3}{*}{ Variable } & \multirow{3}{*}{$\mathbf{N}$} & \multicolumn{2}{|c|}{ ANC utilization } & \multirow{3}{*}{ Odd Ratio } & \multirow{3}{*}{ p-value } \\
\hline & & $<4$ & $>4$ & & \\
\hline & & n (\%) & n (\%) & & \\
\hline \multicolumn{6}{|c|}{ Number of Pregnancies (Gravida) } \\
\hline $1-5$ & 192 & $164(85.5)$ & $28(14.5)$ & 1.000000 & \\
\hline $6-11$ & 148 & $107(72.3)$ & $41(9.5)$ & 2.244326 & 0.0029 \\
\hline 12-above & 67 & $59(88)$ & $8(12)$ & 0.794189 & 0.5910 \\
\hline \multicolumn{6}{|c|}{ Number of children mothers have given birth (Parity) } \\
\hline $1-5$ & 240 & $186(77.5)$ & $54(22.5)$ & 1.000000 & \\
\hline $6-11$ & 119 & $101(84.9)$ & $18(15.1)$ & 0.613861 & 0.1010 \\
\hline 12-abve & 48 & $43(89.6)$ & $5(10.4)$ & 0.400517 & 0.0587 \\
\hline \multicolumn{6}{|c|}{ Complications during pregnancy } \\
\hline Yes & 183 & $156(85.2$ & $27(14.8)$ & 1.000000 & \\
\hline No & 210 & $160(66.7)$ & $50(23.8)$ & 1.805556 & 0.0242 \\
\hline Not applicable & 14 & $14(100)$ & $0(0.0)$ & 0.000000 & 0.1228 \\
\hline
\end{tabular}

Significant where P-value $<0.05=* *$.

\subsection{Association Between Social Cultural and Economic Factors with ANC Service Utilization}

The results in Table 4 show that People motivated to book for ANC and Prevented factors for attending ANC were found to be significant. Mothers who are motivated to book for ANC by others such as health providers were found to be associated with level of utilization of ANC service. Mothers who are motivated to book for ANC by others such as health providers were 6 times more likely to utilize of ANC service compared to people motivated by media, peers and spouse (OR 6.538462, P-value 0.0000).

Mothers who are motivated to book for ANC by parents were found to be associated with level of utilization of ANC service. Mothers who are motivated to book for ANC by parents were 3 times more likely to utilize of ANC service compared to people motivated by media, peers and spouse (OR 3.269231, P-value 0.0040).

Mothers who are motivated to book for ANC by media were found to be associated with level of utilization of ANC service. Mothers who are motivated to book for ANC by media were less likely to utilize of ANC service compared to people motivated by peers, spouse and others such as health providers (OR 0.000000, P-value 0.0418).

Preventive factors such as distance to the health centers were found to be associated with level of utilization of ANC service. Mothers who are far from the health centers were less likely to utilize of ANC service compared to other factors (OR 6.538462, P-value 0.0000).

Table 4. Association between social cultural and economic factors with ANC service utilization.

\begin{tabular}{|c|c|c|c|c|c|}
\hline \multirow{3}{*}{ Variable } & \multirow{3}{*}{$\mathbf{N}$} & \multicolumn{2}{|c|}{ ANC utilization } & \multirow{3}{*}{ Odd Ratio } & \multirow{3}{*}{ p-value } \\
\hline & & $<4$ & $>4$ & & \\
\hline & & $\mathbf{N}(\%)$ & $\mathbf{N}(\%)$ & & \\
\hline \multicolumn{6}{|l|}{ People motivated to book for ANC } \\
\hline Spouse & 324 & $272(84)$ & $52(16)$ & 1.000000 & \\
\hline Parents/guardian & 26 & $16(61.5)$ & $10(38.5)$ & 3.269231 & 0.0040 \\
\hline Peers & 8 & $8(100)$ & $0(0.0)$ & 0.000000 & 0.2180 \\
\hline Media & 22 & $22(100)$ & $0(0.0)$ & 0.000000 & 0.0418 \\
\hline Others & 27 & $12(44)$ & $15(56)$ & 6.538462 & 0.0000 \\
\hline Prevented factors for attending ANC & & & & & \\
\hline
\end{tabular}




\begin{tabular}{|c|c|c|c|c|c|}
\hline \multirow{3}{*}{ Variable } & \multirow{3}{*}{$\mathbf{N}$} & \multicolumn{2}{|c|}{ ANC utilization } & \multirow{3}{*}{ Odd Ratio } & \multirow{3}{*}{ p-value } \\
\hline & & $<4$ & $>4$ & & \\
\hline & & $\mathbf{N}(\%)$ & $\mathbf{N}(\%)$ & & \\
\hline Unplanned pregnancy & 43 & $22(51)$ & $10(49)$ & 1.000000 & \\
\hline Limited Knowledge about ANC & 181 & $180(99)$ & $17(1)$ & 0.000000 & 0.2898 \\
\hline Cultural/ religious factors & 86 & $85(99)$ & $6(1)$ & 0.000000 & 0.1762 \\
\hline Financial constraints & 46 & $45(99)$ & $11(1)$ & 3.269231 & 0.1797 \\
\hline Distance to the health center & 16 & $15(98)$ & $9(2)$ & 0.000000 & 0.0000 \\
\hline Unfriendly health workers attitudes & 8 & $4(50)$ & $6(50)$ & & \\
\hline High ANC fees & 9 & $4(44)$ & $3(56)$ & & \\
\hline Delays in attending to clients & 6 & $6(100)$ & $1(0)$ & & \\
\hline Poor family support and social support & 4 & $4(100)$ & $0(0)$ & & \\
\hline
\end{tabular}

Significant where $\mathrm{P}$-value $<0.05=* *$.

\subsection{Association Between Satisfaction of ANC Services And Utilization Of ANC Services Among Pregnant Mothers}

The results in Table 5: shows that pregnant mothers, who were satisfied quality of ANC, were found to be significant.

Satisfactory of quality of ANC was found to be associated with level utilization of ANC service. Satisfactory opinion was 5 times more likely to utilize of ANC service compared to other opinions such as very good, good and poor (OR 5.1, P-value 0.0001).

Other opinions of quality of ANC services such as very good, good and poor were not significantly associated with level of utilization of ANC service.

Table 5. Association between Quality Of ANC Services And Utilization Of ANC Services Among Pregnant Mothers.

\begin{tabular}{|c|c|c|c|c|c|}
\hline \multirow{3}{*}{ Variable } & \multirow{3}{*}{$\mathbf{N}$} & \multicolumn{2}{|c|}{ ANC utilization } & \multirow{3}{*}{ Odd Ratio } & \multirow{3}{*}{ p-value } \\
\hline & & $<4$ & $>4$ & & \\
\hline & & N (\%) & $\mathbf{N}(\%)$ & & \\
\hline \multicolumn{6}{|c|}{ Quality of ANC service } \\
\hline Very Good & 342 & $286(83.6)$ & $56(16.4)$ & 1.000000 & . \\
\hline Good & 39 & $29(74.4)$ & $10(25.6)$ & 1.761084 & 0.1479 \\
\hline Satisfactory & 22 & $11(50)$ & $11(50)$ & 5.107143 & 0.0001 \\
\hline Poor & 4 & $4(100)$ & $0(0.0)$ & 0.000000 & 0.3774 \\
\hline
\end{tabular}

Significant where P-value $<0.05=* *$.

\section{Discussion}

World Health Organization recommends a minimum of four ANC visits [12] initiated during the first trimester of pregnancy. In this study, the overall ANC attendance was found to be high $18.9 \%$. The study showed that the proportion of the pregnant mothers increased with age. Majority of the pregnant mothers' highest level of education was College/university. This indicated that most women became mothers while at their high level of education. The study however showed, there was no significant relationship between level of education and utilization of ANC services. This finding were contrary with other studies such as an Ethiopian study which indicated that education is likely to enhance female autonomy so that women develop greater confidence and capability to make decisions for their own health. It is also likely that educated women seek higher quality services and have greater ability to use health care inputs that offer better care [13]. As shown by the researh [14], higher level of education has been shown to improve utilization of ANC servicers for women of reproductive age (15-49 years). However, since pregnant mothers are not in a position to make autonomous decision and have no developed greater confidence and capability to make decisions about their own health there was no relationship between level of utilization of ANC services and their educational status. From the findings, Person living with pregnant mother was found to be associated with level of utilization of ANC service. Pregnant mothers living with others were 4 times more likely to utilize ANC service compared to mothers whose parents, spouse and self-living with respectively. This concurred with Upadhyay and others [15] who established that people who lived with the pregnant mothers influenced their decisions on the utilization of antenatal care services. It also concurred with a study by Dallas who observed that the unemployed, single and economically dependent pregnant mothers were not likely to utilize ANC services.

\section{Limitations of the Research}

Despite the contribution of the study to the literature on maternal health care, this study has some limitations. First, it is a cross-sectional study in which temporal relations could not be assessed. Second, the greatest challenge was convincing Somali women to open up and share their thoughts on sensitive and personal topics related to their private life, considered to be a taboo in their culture.

\section{Conclusion and Recommendation}

There is high percentage of pregnant mothers having at 
least one ANC visit (29.0\%); however $18.9 \%$ of them had at least four ANC visits as recommended by WHO. This indicates low utilization of antenatal care services.

In Socio-demographic factors such as Persons living with pregnant mothers, sources of income; Obstetric factors such as parity and socio-cultural factors such as health care providers, media influence and quality of antenatal care were predicting the pattern of antenatal care utilization.

Although $81.8 \%$ of pregnant mothers were aware of the existence of ANC services within Wadajir settlements, utilization was low (18.9\%).

Ministry of Health $(\mathrm{MOH})$ and other stakeholders should come up with specific efforts towards enhancing staff motivation through introduction of incentives and better working environment as this will address staff turnover rates. An environment of responsibility in delivering quality care among providers should be emphasized and a system of monitoring delivery of quality services established.

Ministry of Health $(\mathrm{MOH})$ and other stakeholders should work towards enhancing facility preparedness for quality care for women with complications as this will improve access to adequate care during complications and ease congestion in tertiary facilities. All areas of delays in referral for women with complications should be addressed.

Anyone living with pregnant mothers should encourage them to seek ANC services. There is need for MOH to educate Wadajir residents on importance of ANC services.

There is need to design intervention targeting pregnant mothers of higher parity in order to improve on number of ANC visits as recommended by WHO.

Customized ANC services targeting pregnant mothers should be established to increase uptake. This will address issues related to Cultural influence.

\section{References}

[1] Basha, G. W. (2019). Factors Affecting the Utilization of a Minimum of Four Antenatal Care Services in Ethiopia. Obstetrics and Gynecology International, 2019. https://doi.org/10.1155/2019/5036783.

[2] Clavagnier, I. (2012). Antenatal care. Revue de l'infirmière, 185, 45-46. https://doi.org/10.5005/jp/books/12049 57.

[3] Babar T., Shaikh, and Juanita Hatcher, J. (2004). Health seeking behavior and health service utilization in Pakistan challenging the policy makers. Journal of Public Health, 10.1093 .

[4] Abdullahel Hadi, M. N. M. (2007). The Inaccessibility and Utilization of Antenatal Health-Care Services in Balkh Province of Afghanistan. Asia Pac Popul J, 22 (1).
[5] Caitlin Mazzilli and Austen (2009). Davis Health care seeking behaviour in Somalia - A Literature Review.

[6] Celik, Y. and Hotchkiss, D. R. (2000). The Socioeconomic determinants of maternal health care utilisation in Turkey. Social Science \& Medicine, 50 (12): 1797-806.

[7] Chitime (2006). Determinants of utilisation of antenatal health Care services by pregnant women during the first Trimester of pregnancy in Nsanje. Dissertation submitted in partial fulfilment for the Completion of the masters in public health. University of Malawi.

[8] Dagne, E. (2010). Role of socio-demographic factors on the utilization of maternal health care services in Ethiopia. Department of Public Health, Umea University, Ethiopia.

[9] DrIngvilSorbye and DrBailah Leigh (2010). Somalia reproductive health National strategy plan implementation of the new model. Geneva: WHO Programme to Map Best Ingvilkraruo. (2010). Situation Analysis of reproductive health for Somalia.

[10] Kabue. P. N. (2014). Determinants of utilization of hospital delivery among post-natal mothers in Thika and Kangundo hospitals, Kenya. A thesis submitted in fulfilment of the requirements for the award of the degree of doctor of philosophy in the school of public health of Kenyatta University.

[11] Kipronoh. K. M (2009). Factors influencing the quality of antenatal care in public maternal and child health facilities in Nairobi province, Kenya. A thesis submitted in partial fulfilment of the requirements for the degree of master of public health in the school of health sciences of Kenyatta University.

[12] Abimbola, J. M., Makanjuola, A. T., Ganiyu, S. A., Babatunde, U. M. M., Adekunle, D. K., \& Olatayo, A. A. (2016). Pattern of utilization of ante-natal and delivery services in a semi-urban community of north-central Nigeria. African Health Sciences, 16 (4), 962-971. https://doi.org/10.4314/ahs.v16i4.12.

[13] Regassa, N. (2011). Antenatal and postnatal care service utilization in Southern Ethiopia: A population-based study. African Health Sciences, 11 (3), 390-397.

[14] Upadhyay, P., Liabsuetrakul, T., Shrestha, A. B., \& Pradhan, N. (2014). Influence of family members on utilization of maternal health care services among teen and adult pregnant women in Kathmandu, Nepal: A cross sectional study. Reproductive Health, 11 (1), 1-11. https://doi.org/10.1186/1742-4755-11-92.

[15] World Health Organization. (2018). WHO recommendation on antenatal care contact schedules. The WHO Reproductive Health Library, March, 1-7. https://extranet.who.int/rhl/topics/improving-health-systemperformance/who-recommendation-antenatal-care-contactschedules. 